\title{
A audiência de conciliação e de mediação do artigo 334: questões controvertidas no código de processo civil de 2015 - CPC. ${ }^{1}$
}

\section{The conciliation and mediation hearing of the article 334: controversial issues in the code of civil procedure of 2015 - CPC.}

Fabiana Marion Spengler ${ }^{2}$ Theobaldo Spengler Neto ${ }^{3}$

\section{Resumo:}

O presente artigo tem como tema de pesquisa debater a audiência de conciliação e de mediação proposta no Código de processo Civil de 2015. Nesse sentido, o debate pretendeu responder ao seguinte questionamento: o momento de realização da audiência de conciliação e de mediação poderá ser flexibilizado, ocorrendo tal ato posteriormente àquele da previsão legal (artigo 334 CPC)? E a multa, prevista no parágrafo $8^{\circ}$ do artigo 334, poderá/deverá ser sempre aplicada? Assim, o objetivo geral é discutir a redação trazida pela Lei Processual Civil e a (im)possibilidade de interpretações extensivas, pretendendo colaborar com o debate quanto à possibilidade ou não de ser esta audiência (artigo 334) realizada em momento posterior, com a mesma penalização (parágrafo $8^{\circ}$ ). Como objetivo específico tem-se o de analisar a aplicabilidade da penalização (artigo 334, parágrafo $8^{\circ}$ ) às partes que não comparecerem à sessão de mediação designada e a caracterização de ato atentatório à dignidade da justiça, na medida em que não referida expressamente no texto legal. Para fins de cumprir com o proposto, o método de abordagem utilizado foi o dedutivo, partindo da relação entre argumentos gerais, denominados premissas, para argumentos particulares, até se chegar a uma conclusão. Como método de procedimento foi utilizado o método monográfico, a partir da leitura e fichamentos de fontes bibliográficas ligadas ao tema da pesquisa.

\section{Palavras-chave:}

Autocomposição, audiência, mediação, conciliação, Código de Processo Civil.

\footnotetext{
${ }^{1} \mathrm{O}$ presente artigo foi produzido no âmbito do projeto de pesquisa intitulado "A mediação e a conciliação como políticas públicas autocompositivas de acesso à justiça no Código de Processo Civil brasileiro (CPC)", financiado pela Universidade de Santa Cruz do Sul - UNISC e do qual fazem parte a primeira autora como coordenadora e o segundo autor como pesquisador.

${ }^{2}$ Doutora em Direito pela Universidade do Vale do Rio dos Sinos e e pós-doutora pela Universidade degli Studi di Roma Tre. Professora adjunta da Universidade de Santa Cruz do Sul nas disciplinas Direito Civil - Família, Processo Civil I, Mediação e Arbitragem, e na pós graduação junto ao Programa de Mestrado e de Doutorado em Direito as disciplinas de "Políticas Públicas no Tratamento de Conflitos" e "Políticas Públicas para uma nova jurisdição"

3 Mestre em Direito pela Universidade de Santa Cruz do Sul (2000). Professor adjunto da Universidade de Santa Cruz do Sul.
} 


\begin{abstract}
:
This article discusses the conciliation and mediation hearing proposed in the Code of Civil Procedure of 2015. In this sense, the debate aims to answer the following questions: the moment of the conciliation and mediation hearing can be more flexible, and can this act occur later than the one in the legal provision (article $334 \mathrm{CCP}$ )? And the fine, predicted in the $\S 8^{\circ}$ of the article 334, can/should always be applied? Thus, the general objective is to discuss the Civil Procedure Law and the (im)possibility of extensive interpretations, intending to collaborate with the debate as to whether or not this hearing (article 334) and penalty $\left(\$ 8^{\circ}\right)$ are possible when done in a different time frame than the one prescribed. The specific objective is to analyze the applicability of the penalty (article $334, \S 8^{\circ}$ ) to the parties that do not attend the designated mediation session and if it characterizes an act that threatens the dignity of justice, as it is not written/express in the Legal text in order to comply with the proposed. The method of approach used was the deductive, starting from the relation between general arguments, called premises, to particular arguments, until a conclusion is reached. As method of procedure was used the monographic method, from the reading and records of bibliographic sources linked to the researched theme.
\end{abstract}

\title{
Keywords:
}

Self-composition, hearing, mediation, conciliation, Code of Civil Procedure.

\section{INTRODUÇÃO}

A busca pela autocomposição sempre foi uma determinação aos julgadores. Trata-se de proporcionar que as partes possam, de modo consensual, chegar a um resultado que evite o recrudescimento de um litígio já posto. No direito processual brasileiro muitas foram as tentativas de emprestar efetividade ao momento conciliatório. Somente nos 43 anos de existência do Código de Processo Civil de 1973, várias alterações foram produzidas. Agora, diante do caderno processual civil, vê-se a previsão de um novo momento e de uma nova forma: a audiência de conciliação e mediação, tratada no artigo 334.

Porém, importa repensar a forma e o momento. Como não poderia ser diferente - estáse tratando do Código de Processo Civil - a atual tentativa vai em busca da finalização das demandas já existentes. Ou seja, a composição resultará na finalização de uma ação judicial já posta, tendo acarretado na oneração financeira e emocional das partes.

Paralelamente a esse caminho, importante, sem dúvida alguma, viu-se sancionado outro instrumento de autocomposição, o qual merece atenção em razão do seu momento de oportunização. A Lei 13.140, de 26 de junho de 2015 veio regulamentar o instituto da mediação e, agora, no âmbito anterior ao da tutela jurisdicional. A mediação pré-processual 
traz duas grandes vantagens às partes: a primeira é a redução do custo financeiro em busca da solução, que beneficia também ao estado-juiz, que estará vendo diminuir o número de demandas que lhe são postas; a segunda, mas não menos importante, é obtenção do resultado positivo por meio da autocomposição mediada.

Entretanto, a soma dos dispositivos, CPC e Lei de Mediação, mas em especial o primeiro, merece atenção ao tratar da forma e momento como serão interpretadas as normas. O CPC indica o momento para a realização da audiência, como sendo o primeiro ato após a citação. O prazo processual destinado à defesa do demandado passará a correr somente após findas as tentativas de autocomposição. De outra banda, torna esse momento coercitivo às partes, salvo que se manifestem expressamente quanto ao desinteresse, em tempo hábil. A ausência ao ato acarretará na caracterização de ato atentatório à dignidade da justiça.

Diante de tais colocações a pesquisa pretendeu responder ao seguinte questionamento: o momento de realização da audiência de conciliação e de mediação poderá ser flexibilizado, ocorrendo tal ato posteriormente àquele da previsão legal (artigo $334 \mathrm{CPC}$ )? E a multa, prevista no parágrafo $8^{\circ}$ do artigo 334 , poderá/deverá ser sempre aplicada?

Nesses termos, o presente estudo busca discutir a redação trazida pela Lei Processual Civil e a (im)possibilidade de interpretações extensivas. Pretende colaborar com o debate quanto à possibilidade ou não de ser esta audiência (artigo 334) realizada em momento posterior, com a mesma penalização (parágrafo $8^{\circ}$ ). Ainda, se aplicável às partes, que não comparecerem à sessão de mediação designada na forma do artigo 334, a caracterização de ato atentatório à dignidade da justiça, na medida em que não referida expressamente no parágrafo $8^{\circ}$.

Para fins de cumprir com o proposto, o método de abordagem utilizado foi o dedutivo, partindo da relação entre argumentos gerais, denominados premissas, para argumentos particulares, até se chegar a uma conclusão. Como método de procedimento foi utilizado o método monográfico, a partir da leitura e fichamentos de fontes bibliográficas ligadas ao tema da pesquisa.

O primeiro tópico do presente artigo trata da audiência de conciliação no tempo, trazendo um histórico desse instituto no decorrer da organização processual brasileira até o ano de 2015, quando então, no segundo item, se exporá o modo como o atual CPC trata da matéria. $\mathrm{O}$ item três trata da autocomposição no $\mathrm{CPC}$ e as divergências de interpretação surgidas com aspectos dúbios da nova legislação, encaminhando-o texto para a conclusão. 


\section{AUDIÊNCIA DE CONCILIAÇÃO NO TEMPO}

A conciliação sempre foi objetivo levado aos julgadores, de modo a proporcionar a autocomposição. E, tratando do envolvimento desse poderoso terceiro - juiz -, está-se diante da autocomposição judicial que, na fala de Calmon (2013, p. 132) denomina-se por "a solução do conflito praticada pelas próprias partes envolvidas quando a posterior homologação judicial". Conciliação, prossegue, entretanto, "é a atividade desenvolvida para incentivar, facilitar e auxiliar a essas mesmas partes a chegarem a um acordo".

O dever de buscar a concórdia já era imposto ao juiz nas Ordenações Filipinas, como mostra Castro Filho (1953, p. 278) ${ }^{4}$ :

E no começo da demanda dirá o juiz a ambas as partes, que antes que façam despesas e sigam entre eles os ódios e dissensões, se devem concordar, e não gastar suas fazendas, por seguirem suas vontades, porque o vencimento da causa sempre é duvidoso (sic).

Dessa forma tinha-se a conciliação em caráter preparatório, obrigatório, como condição para que a ação fosse recebida.

A primeira Constituição do Império, de 25 de março de 1824, consagrou o instituto da conciliação, elevando-o a categoria de preceito constitucional, quando no artigo 161 restou estabelecido que "sem se fazer constar que se tem intentado o meio da reconciliação, não se começará processo algum” (ABREU, 2007, p. 13). O preceito era determinante.

O Regulamento 737, de 25 de novembro de 1850, de forma ainda mais objetiva, em seu artigo 23, determinava que "nenhuma causa comercial será proposta em juízo contencioso, sem que previamente se tenha tentado o meio da conciliação, ou por ato judicial ou por comparecimento voluntário das partes" (CASTRO FILHO, 1953, p. 278). Entretanto, importa registrar que essa obrigatoriedade restringia-se às "causas comerciais".

No âmbito da Justiça do Trabalho, o Decreto 21.396, de $1^{\circ}$ de maio de 1932 instituiu as Comissões Mistas de Conciliação, que inspiraram as Juntas de Conciliação e Julgamento (CASTRO FILHO, 1953, p. 281), hoje não mais assim conhecidas. O dever de tentar conciliar, porém, permanece intacto.

\footnotetext{
${ }^{4}$ Interessante leitura pode ser feita no artigo do Professor José Olímpio de Castro Filho intitulado "A conciliação no Processo Civil” publicado em 1953. Traz um recorte histórico do dever imposto aos juízes pela busca da autocomposição.
} 
O Código de Processo Civil de 1939, denominado de Código Unitário, porque instalava uma legislação processual nacional em vigor para todas as unidades federativas, omitiu a conciliação. Muito embora moderno para a época, prévio apenas a audiência de instrução, sem nela inserir a obrigatoriedade ao juiz de buscar os meios compositivos.

O Código de 1973 é um marco para o direito processual. Já preocupado com a demora da prestação jurisdicional o CPC de 1973 traz o procedimento sumaríssimo, o qual, porém, não se mostrou eficaz. O tempo, o aumento da judicialização das mazelas humanas e mesmo os efeitos econômicos nacionais refletiram no processo, exigindo modificações.

A conciliação passou a ser um dos deveres do juiz somente por meio da Lei 8.952/1994, quando o artigo 125 foi complementado para atribuir o dever de "IV - tentar, a qualquer tempo, conciliar as partes”. A mesma Lei tratou de alterar a fase do saneamento do processo (art. 331). Inseriu a determinação de designação de audiência de conciliação ${ }^{5}$. $\mathrm{O}$ ato de saneamento ocorreria somente após.

Mais uma vez o tempo demonstrou a necessidade de ajustes. A "audiência de conciliação" deu lugar à "audiência preliminar", por força da Lei 10.444/2002. Nesta, na nova redação do artigo 331 do CPC de 1973, o ato de conciliação seria prévio ao saneamento, o qual deveria nela ocorrer. Estava-se diante do encerramento da fase postulatória ${ }^{6}$. Esta redação manteve-se até 18 de março de 2016.

Ainda no ano de 2010 iniciou uma caminhada em busca de um "novo" Código de Processo Civil. Notáveis processualistas como Teresa Arruda Alvin Wambier ${ }^{7}$, a quem coube a relatoria, e sob a presidência do Ministro Luiz Fux, debateram com a sociedade jurídica nacional novos caminhos para o processo civil brasileiro. Entra em vigor, seis anos após, o Código de Processo Civil de 2015. Elogiado e criticado, mas debatido. Tem-se o mais humano dos cadernos processuais até então vistos.

\section{AUDIÊNCIA DE CONCILIAÇÃO OU DE MEDIAÇÃO NO CPC/2015}

\footnotetext{
${ }^{5}$ Esta audiência somente não deveria ser designada no caso de cabimento de julgamento do processo no estado em que se encontrava, ou sendo indisponíveis os direitos postos.

${ }^{6}$ Ou seja, a ideia era de proporcionar espaço para a autocomposição somente após pelas partes estar postos os seus argumentos. Todas as falas estariam presentes, com seus rancores e suas iras.

7 Também, Adroaldo Furtado Fabrício Benedito Cerezzo Pereira Filho Bruno Dantas ElpídioDonizetti Nunes Humberto Theodoro Júnior Jansen Fialho de Almeida José Miguel Garcia Medina José Roberto dos Santos Bedaque Marcus Vinicius Furtado Coelho Paulo Cesar Pinheiro Carneiro. A estes outros, tão reconhecidos quanto os primeiros, se juntaram quando a matéria passou a ser discutida na Câmara de Deputados.
} 
Objetivando a redução do tempo das demandas o Conselho Nacional de Justiça estabeleceu como prioridade a busca de caminhos para que o jurisdicionado pudesse atingir resultados de forma mais célere e consensual. Como já sinalizou Fabiana Marion Spengler (2014, p. 73):

\footnotetext{
mais que um meio de acesso à justiça, fortalecedor da participação social do cidadão, a mediação e a conciliação são políticas públicas que vêm ganhando destaque e fomento do Ministério da Justiça, da Secretaria de Reforma do Judiciário e do CNJ brasileiros, uma vez que resta comprovada empiricamente sua eficiência no tratamento de conflitos. Prova disso é a Resolução 125, de 29.11.2010 do CNJ que versou sobre a "Política Judiciária Nacional de Tratamento Adequado dos Conflitos.
}

A partir da Resolução 125 os Tribunais deveriam criar Núcleos Permanentes de Métodos Consensuais de Solução de Conflitos, com atribuição de estimular a busca por meios adequados de solução de conflitos. Os núcleos deveriam, inclusive, gestar a mediação comunitária, mediação penal ou qualquer outro meio restaurativo.

Novos ventos sopraram para alocar a audiência de conciliação ou de mediação para um momento processual mais apropriado. Ao receber a petição inicial "o juiz designará audiência de conciliação ou de mediação com antecedência mínima de 30 (trinta) dias, devendo o ser citado o réu com pelo menos 20 (vinte) dias de antecedência”. É o que determina o artigo 334 do atual Código, único destinado ao tema. Ou seja, nenhum ato processual, salvo de urgência, poderá ser realizado.

\subsection{Procedimento a ser adotado em busca da autocomposição ${ }^{8}$}

Nessa esteira o CPC trouxe a ideia de inovar no caminho inicial das demandas. Incentiva a atuação - não haveria uma presidência, mas um terceiro cooperador - na audiência de conciliação ou de mediação. Mostra o parágrafo $1^{\circ}$ do artigo 334, que onde houver quadro de conciliadores e de mediadores, estes deverão atuar, sempre sob a batuta das normas ditadas pelo Conselho Nacional de Justiça - CNJ.

Vem a nova audiência que possibilita que as partes debatam seus dilemas e direitos antes de acirrados os ânimos com defesa e exaustiva fase probatória. Possibilita que o diálogo

\footnotetext{
${ }^{8}$ Esse assunto será melhor desenvolvido adiante.
} 
seja mais leve, ante o momento inicial da demanda. A proposta de diálogo, senão prévio, antecedente ao debate (SPENGLER NETO, ZUCHETTO, FERREIRA, 2016). Também por definição legal, permite que as partes possam prosseguir no diálogo intermediado por conciliador ou por mediador, por até dois meses a contar da primeira oportunidade (parágrafo $2^{\circ}$ do artigo 334). Trata-se de uma oportunidade de valorizar o real interesse pela composição. No entanto importa respeitar a vontade das partes, na medida em que delas é o tempo destinado ao debate. Em especial para uma mediação de conflitos eficaz não se pode estabelecer limites de tempo, na medida em que retrata diálogo e compreensão mútuos. Tantas sessões devem ser realizadas quantas necessárias para a maturação do entendimento comum (SPENGLER, 2016, a). Ou, como ensina Bueno (2016, p. 318), "o dispositivo quer viabilizar que o tempo necessário à conciliação e à mediação seja empregado para evitar, é este seu intuito, a solução imposta".

Assim como cabe as partes definir a utilização do tempo hábil para o diálogo, também delas é a definição pela realização ou não do ato ${ }^{9}$. O parágrafo quarto do artigo 334 estabelece duas hipóteses de não realização da audiência: a primeira delas, quando as partes (importa registrar o uso do plural) assim registrarem expressamente ${ }^{10}$. O desejo quanto a realização da audiência de conciliação ou de mediação, pelo autor, deve ser expressa na petição inicial, caracterizando como requisito essencial para o seu recebimento (artigo 319, VII).

De outra banda, dispõe o parágrafo quinto que o réu deverá informar o seu desinteresse na autocomposição no prazo de dez dias anteriores à data agendada. Ainda, o parágrafo sexto informa da necessidade de manifestação de todos os litisconsortes, para que o ato seja suspenso. Ou seja, o objetivo é, de modo claro, oportunizar o encontro entre as partes, possibilitando o diálogo franco. Até porque, "seria um despropósito impor a conciliação e

\footnotetext{
${ }^{9}$ Como bem demonstra Spengler (2016 a,p. 110) ao abordar os conciliadores e mediadores como auxiliares da justiça, em especial o artigo 166 , parágafo. $4^{\circ}$, do $\mathrm{CPC}$, “O $\S .4^{\circ}$ aponta que a conciliação e a mediação serão regidas conforme a autonomia dos interessados, inclusive quanto a definição das regras procedimentais". Ou seja, cabe às partes o poder de decidir quanto ao interesse pela audiência tratada pelo artigo 334, CPC.

${ }^{10}$ Neste ponto vale informar a interpretação respeitável de Medina (2016, p. 582) quanto a possibilidade de não realização da audiência e mesmo aplicação de penalidade quando uma das partes julgá-la inconveniente: “A manifestação prévia de qualquer das partes no sentido de não haver interesse na autocomposição frustra, desde logo, o desiderato da audiência. São muitos os motivos que nos conduzem a esse modo de pensar". Justifica o autor informando que (a) é o próprio caput do artigo 334 que permite a não realização da audiência quando for caso de julgamento liminar do pedido; (b) tanto conciliação quanto a mediação são informadas pelo princípio da autonomia da vontade; (c) a cultura da pacificação não pode ser imposta, dentre outras. Na mesma linha PINHO (2016, p. 449) que sobre o tema afirma "Estamos em que o magistrado deva ter discricionariedade para avaliar se a audiência de conciliação ou de mediação será útil ou não, diante do que consta nos autos”.
} 
mediação quando as partes se manifestaram expressamente em sentido contrário" (ALVIN, WAMBIER, et al., 2015, p. 571).

A partir desse novo momento, qual seja, proporcionar a autocomposição como primeiro passo processual após o aforamento do pedido, nasce a discussão quanto à interpretação da obrigatoriedade do ato. Sem motivos, salvo melhor juízo, como se verá.

O parágrafo oitavo do artigo 334, apresenta penalização à parte que, injustificadamente, não comparece à audiência de conciliação designada. Caracteriza a omissão como ato atentatório à dignidade da justiça, impondo-se multa de $2 \%$ (dois por cento) da vantagem econômica (valor da causa). Então, tem-se o dever (e não ônus) de estar presente ao ato, mas não de "negociar".

Ou seja, está-se diante de um racional lógico-jurídico simples: deve o juiz designar audiência de conciliação ou de mediação, exceto nos casos especificamente referidos no caput do artigo 334, CPC; as partes tem a disponibilidade de decidir se desejam ou não submeter-se ao ato designado pelo juiz e, sendo consensual a negativa, deve ser cancelada a audiência; uma vez realizada a audiência e presentes as partes, é sua a decisão quanto a efetiva participação ou não da conciliação ou da mediação, bastando que seja comunicado a quem conduza o ato o desinteresse na autocomposição.

Portanto, a interpretação de ser "a conciliação" ou "a mediação" obrigatórias, ou mesmo obrigatória a submissão é equivocada. O que o novo caderno processual civil pretende é incentivar a autocomposição, mas não obrigá-la. O artigo 334, em seus parágrafos nono e décimo, informa ainda da atuação do advogado ou defensor público. Sua presença é indispensável, como garantia de um processo democrático ${ }^{11}$. Poderá a parte fazer-se representar, porém caso o representante detenha poderes especiais para transigir.

Findando a análise desse artigo, está-se diante de uma norma específica. Estabelece o parágrafo segundo que "a pauta das audiências de conciliação ou de mediação será organizada de modo a respeitar o intervalo mínimo de 20 (vinte) minutos entre o início de uma e o início da seguinte". Spengler (2016 a , p. 118) aponta sobre o tema:

talvez nesse interregno seja possível fazer uma conciliação. Porém, fazer uma mediação bem feita, com todas as suas etapas e técnicas, ou então utilizando-se daquelas que foram necessárias, permitindo o diálogo e a troca criativa de propostas, dificilmente se concretizará em apenas 20 minutos. Nesse sentido, como a

\footnotetext{
${ }^{11}$ Lembrando a norma constitucional tratada pelo art. 133 da Carta Magna, que aponta ser o advogado essencial para a administração da justiça.
} 
disposição legal fala de "intervalo mínimo" será necessário contar com o bom senso do juiz na organização da pauta oferecendo aos mediadores mais tempo para desenvolver de maneira adequada o seu trabalho.

Além da compreensão dos magistrados do tempo de cada mediação, a capacidade de argumentação dos conciliadores e dos mediadores quanto a possibilidade de redesignação do ato, na forma do parágrafo segundo deste mesmo artigo 334. Basta que as partes assim entendam viável.

\subsection{Meios autocompositivos nas ações de família e nas ações possessórias coletivas}

Este Código, que parece mais humano no trato dos dilemas dos cidadãos, cria normas gerais para o trato das ações de família (artigos 693/699). Aquelas ações que transitam pelos sentimentos humanos mais suscetíveis ao sofrimento. Uma dessas regras diz respeito a utilização da mediação para lidar com os conflitos familistas.

Tal se dá porque a mediação familiar poderá ser uma alternativa mais vantajosa, mais próxima e menos dolorosa de tratamento desses conflitos, justamente porque é um procedimento interdisciplinar que pretende conferir aos seus envolvidos autonomização e responsabilização por suas próprias decisões, convidando-as à reflexão e ampliando escolhas e alternativas ${ }^{12}$. É não adversarial pois pretende desconstruir impasses que impedem a comunicação $^{13}$, transformando um contexto de confronto em contexto colaborativo. É um procedimento confidencial e voluntário no qual o mediador, terceiro imparcial, facilita e promove a comunicação entre os conflitantes. Consequentemente, o acordo pode ser um dos desfechos possíveis, mas ainda que ele não ocorra, se o diálogo amistoso foi restabelecido, a mediação poderá ser considerada exitosa.

Nesse mesmo sentido, observa-se que a mediação familiar é um procedimento "imperfeito que emprega uma terceira pessoa imperfeita para ajudar pessoas imperfeitas a concluir um acordo imperfeito em um mundo imperfeito" (MARLOW, 1991, p. 31).

\footnotetext{
${ }^{12}$ La mediazione è uno strumento flessibile, che aiuta la famiglia a mettere in gioco le capacità di soluzione del disaccordo piutosto che lavorare sull'aument del disagio; si attua tra genitori e figli, tra marito e moglie, nella gestione di attività della famiglia o nel dare risposta a problemi di vario genere: il cambiamento di residenza, la malattia dei nonni, la scelta degli studi, una decisione importante come comprare una casa, imbiancare l'appartamento, progettare le vacanze (GIOMMI, 2006, p. 65).

${ }^{13}$ Sobre o tema é importante a leitura de ROSENBERG (2006).
} 
Especificamente no âmbito familista a mediação é o processo que, através do uso de técnicas de facilitação, aplicadas por um terceiro interventor numa disputa, estabelece o contexto do conflito existente, identifica necessidades e interesses, mediante recursos advindos da psicologia e da assistência social, produzindo decisões consensuais, posteriormente traduzidas em um acordo levado ou não à homologação.

Justamente porque utiliza os conhecimentos e os serviços de áreas próximas porém diferentes (Direito, Psicologia e Serviço Social) a mediação familista é considerada uma prática transdisciplinar que se utiliza do trabalho de um mediador e de um ou mais comediadores que formam uma equipe multidisciplinar com várias competências que se complementam entre si, oferecendo as partes uma assistência integral. O papel da transdisciplinaridade é justamente constituir um conhecimento em rede que permita a integração de diferentes paradigmas para atender necessidades diversas (MUSZKAT; - et al. OLIVEIRA; UNBEHAUM; MUSZKAT, 2008, p. 48-49).

Por conseguinte, enquanto instrumento de difusão e aprimoramento da prática e do pensamento interdisciplinar, a mediação empresta ao fenômeno jurídico - e aqui leia-se direito familista - a necessária visão da complexidade inerente ao ser humano. Tal se dá porque a mediação inter/transdisciplinar apela ao ser profissional da área de ciências humanas, requerendo o exercício da empatia contribuindo para a formação e prática de um novo paradigma que vá além da cultura do litígio (GROENINGA, 2007, p. 152-170).

Nesse sentido, e objetivando fomentar a mediação e tornando o processo familista mais humano, o artigo 694 informa da importância da busca pela autocomposição. Traz a possibilidade de suspensão do processo, por requerimento das partes pelo tempo necessário a utilização dos meios autocompositivos, mesmo extrajudiciais. Como ressalta Medina (2016, p. 869), nestes tipos de ações não se estará diante do exercício de opção pelas partes, quando a designação da audiência, mas sim de um espaço no qual se tem "primazia absoluta à solução consensual dos conflitos". Assim, prossegue o autor, "dificilmente deixará de ser realizada a audiência de conciliação ou de mediação".

Nessa linha o artigo 696 traz a possibilidade de realização de "tantas sessões quantas sejam necessárias para viabilizar a solução consensual”. Ou seja, a limitação dos dois meses tratada no parágrafo segundo do artigo 334 não é aplicada.

Outra novidade legislativa é a citação do réu sem que, ao mandado respectivo, esteja apensa a petição inicial. Buscando a redução do nível do conflito, o artigo 695 do CPC 
determina que o ato citatório seja realizado sem que cópia da petição inicial o acompanhe. Pretende que a audiência de mediação e conciliação seja realizada sem que ele, réu, tenha sido atingido pelos termos de uma petição inicial, por vezes, repleta de emoção desmedida. Entretanto, e resguardando o necessário direito à ampla defesa e ao contraditório (artigo $5^{\circ}$, LV, da Constituição Federal) poderá ele, réu, "examinar seu conteúdo a qualquer tempo" (parágrafo $1^{\circ}$ ).

Nesse sentindo, ao se referir a regra do artigo 695, parágrafo $1^{\circ}$ (citação sem a cópia da petição inicial) Fernanda Tartuce (2016, p. 337) se manifesta:

a regra, porém, desafia a Constituição Federal: ao permitir que apenas uma das partes tenha ciência do que foi apresentado ao juiz, ela promove um desequilíbrio anti-isonômico no processo; se uma das partes apresentou sua versão em juízo, é decorrência do contraditório que haja sua cientificação.

Além disso, o parágrafo em comento atinge um dos princípios básicos da mediação que diz respeito a decisão informada, que determina a necessidade dos partícipes da mediação de estar informados a respeito do contexto no qual estão inseridos e do processo que contra eles é movido. Está-se diante da conjugação de dois institutos inseparáveis, na moderna visão processual: ações de família e autocomposição.

Ainda em linha de proteção apropriada às demandas especiais, tem-se a designação de audiência de mediação nas ações possessórias com polo passivo coletivo (art. 565, CPC). Essa é uma iniciativa pioneira do atual CPC que determina a realização da mediação para tratar de litígios relativos a posse consolidada (existente a mais de um ano) ${ }^{14}$. Essa mesma previsão se aplica também aos conflitos sobre propriedade imobiliária.

Porém, para que a mediação seja exitosa são necessários o empenho e a cooperação de todos os envolvidos, mediante a aplicação de métodos que viabilizem o debate. Como os direitos inerentes a relação entre a pessoa e seus bens, chamado de "Direito das Coisas" é totalmente disponível, em função de seu cunho patrimonial, "a mediação pode ser um mecanismo propício para obter a saída consensual para eventuais pendengas envolvendo posse e o direito de propriedade em suas diversas gradações” (TARTUCE, 2015, p. 327).

\footnotetext{
${ }^{14}$ Se denominará velha a posse quando estiver sendo exercida há mais de ano e dia. Sua desconstituição dependerá de vias ordinárias, ou de ampla discussão, não se procedendo sumariamente. Aos interditos possessórios não se concederá a reintegração ou a manutenção preliminar (RIZZARDO, 2014).
} 
Para fins de enfrentar o debate é preciso esclarecer o que são conflitos coletivos. Esses conflitos "são, por natureza, causas de grande complexidade, pois evolvem, de um lado, uma numerosidade de titulares de um direito, e de outro lado, normalmente, órgãos públicos que tenham competência na proteção desses direitos" (SPENGLER NETO; CROHMAL; SCHWANTES, 2016, p. 25). Cabe então ao Judiciário o desafio de oferecer resposta qualitativa e viável aos conflitantes envolvidos nessas ações. Nestes termos, a mediação, que objetiva o resgate da comunicação, se encaminha como um mecanismo interessante para alcançar solução juridicamente viável que atenda a todos os interesses envolvidos.

Quando se fala de litígio coletivo pela posse do imóvel pode-se exemplificar citando "as ações possessórias podem envolver pretensões de centenas de famílias que coabitam um único imóvel invadido". Então, é importante que a mediação seja aplicada com "habilidade para trabalhar primeiramente as divergências dentro do grupo de forma igualitária, para posteriormente tratar o conflito de forma globalizada" (SPENGLER NETO; CROHMAL; SCHWANTES, 2016, p. 25).

É importante salientar que a regra do artigo 565 se aplica para a disputa de direito sobre propriedade coletiva, ou litígio coletivo pela posse do imóvel (caput). Mas não só à tutela da posse, pois o parágrafo $5^{\circ}$ determina a aplicação das novas regras também 'ao litígio sobre propriedade de imóvel' (BUENO, 2015, p. 382). Nesse sentido, o caput do artigo em comento dispõe que sua aplicação deve se dar em o esbulho ou turbação tenham ocorrido há mais de um ano e um dia. Nasce então uma primeira crítica à redação do dispositivo. "Os artigos 558 e 562, ambos do mesmo CPC, conduzem à interpretação de que as medidas liminares somente serão deferidas quando a demanda for ajuizada no tempo de um ano e um dia. Passado este, estar-se-ia diante de ação de "força velha", a qual não permite o deferimento de medida de urgência" (SPENGLER NETO; CROHMAL; SCHWANTES, 2016, p. 29).

Porém, a redação traz interpretação polêmica pois "tratando-se de demanda aforada após a perda da posse e passados mais de um ano e dia, inviável o deferimento de medida liminar”. (SPENGLER NETO; CROHMAL; SCHWANTES, 2016, p. 29). Mas, a redação confusa leva a compreender que, "tratando-se de força nova, não seria possível a designação de data, local e hora para a realização da sessão (audiência) de mediação. Por evidente que não deve ser esse o racional do julgador, na medida em que o intento é a solução por meio de autocomposição" (SPENGLER NETO; CROHMAL; SCHWANTES, 2016, p. 29). 
Mas, como afirma Wambier et al. (2015, p. 931), não se trata da medida liminar possessória já referida no artigo 562 do CPC. Ela está vinculada ao prazo de ano e dia (artigo 558), ou seja, somente poderá ser deferida se caraterizada a perda da posse ocorrida a menos de ano e dia. A medida liminar a que se refere o artigo 565 está vinculada às tutelas de urgência regradas pelos artigos 300 e seguintes.

Porém, conforme Medina (2016, p. 825), “justifica-se o cuidado do legislador, se considerada a função social da posse do imóvel: a não oposição à turbação ou ao esbulho por mais de ano e dia permite deduzir haver pouco interesse em proteger a posse, de um lado, de outro lado, que aqueles que ocupam o imóvel podem estar a lhe dar destinação adequada”. Partindo da premissa temporal, o legislador determina que, antes de apreciar eventual pedido de medida liminar, o juiz designe audiência (sessão) de mediação, no prazo de 30 dias, respeitando a urgência do tema.

O parágrafo $1^{\circ}$ do artigo 565 dispõe que, se deferida a medida liminar pleiteada, se não for executada no prazo de um ano a partir da distribuição cabe ao juiz oportunizar a mediação. No parágrafo $2^{\circ}$ fica determinada a intimação do Ministério Público e da Defensoria Pública (quando a parte gozar de justiça gratuita) para comparecer a mediação. Assim, observa-se a inserção de terceiros no contexto mediativo.

E esses terceiros não compõem o espaço de mediação tradicional, ou seja, não serão mediadores, mas sim partícipes ativos. Na forma do parágrafo segundo, existe imposição da intimação do Ministério Público e da Defensoria Pública2. Já na forma do parágrafo quarto, poderá o juiz determinar a intimação dos "órgãos responsáveis pela política agrária e pela política urbana da União, de Estado ou do Distrito Federal e de Município onde se situe a área objeto do litígio...”. São dois os objetivos da presença desses órgãos: primeiro, para que se manifestem quanto ao interesse na área, na medida em que prevalece o interesse público ao privado. Em segundo lugar, para que apresentem oportunidades de solução do litígio no âmbito social. Cabe, entretanto, pontuar que esses terceiros não se confundem com o mediador (SPENGLER NETO; CROHMAL; SCHWANTES, 2016, p. 30-31).

Porém, os terceiros que participação da mediação não são mediadores e por isso a interrogação que se impõe é se realmente o procedimento adotado deverá ser o mediativo ou se a conciliação se aplicaria com maior eficácia.

\subsection{Diferenciação necessária: conciliação e mediação}


As normas legais que tratam do tema "mediação e conciliação" como políticas públicas de tratamento adequado das disputas não as diferencia com clareza, tratando-as como se fossem institutos idênticos, com as mesmas características e servindo ao mesmo tipo de conflitos. Porém, as diferenças entre elas são significativas e importantes.

Elas se dão quanto à conceituação propriamente dita, mas também operam de modo expressivo no papel desempenhado pelos operadores que administram as sessões, pelo tipo de conflito nelas tratados, pelos objetivos perseguidos e pelos resultados almejados. Porém, antes de diferenciar mediação e conciliação faz-se necessário referir que ambas estão elencadas como métodos autocompositivos ${ }^{15}$ de tratamento dos conflitos, colocando-se em contraponto aos chamados heterocomposivos ${ }^{16}$.

A principal diferença entre autocomposição e heterocomposição diz respeito ao fato de que, enquanto nos processos heterocompositivos, cujos modelos são chamados adversariais (arbitragem e jurisdição) há sempre vencedores e vencidos (ganha/perde), nos processos autocompositivos de modelos consensuais (negociação, mediação e conciliação) buscam-se as soluções vencedoras (ganha/ganha), observando os interesses de todos (BACELLAR, 2011).

Tal se dá porque a mediação constitui um procedimento de transformação dos antagonismos em pontos de convergências, não necessariamente em pontos de concordância, mediante a intervenção de um terceiro escolhido pelos conflitantes. A mediação consiste em um "dos instrumentos de pacificação de natureza autocompositiva e voluntária, no qual um terceiro, imparcial, atua, de forma ativa ou passiva, como facilitador do processo de retomada do diálogo entre as partes, antes ou depois de instaurado o conflito" (CAHALI, 2015, p. 85). O mediador tem, então, a tarefa de possibilitar que conflitantes expressem seus sentimentos e seus interesses dando a eles espaço para, de modo criativo, formular sugestões e propostas para a Resolução adequada de seu conflito. O mediador não tem papel ativo na proposição de acordos, nem na orientação das partes quanto ao conflito. Essa tarefa não é da sua alçada.

\footnotetext{
15 “A autocomposição tem por princípios a indivisibilidade e a interpretação restritiva. Seu principal efeito é fazer desaparecer o litígio. Se judicial, dá causa ao fim do processo; se preventiva, evita-o. Os escopos da autocomposição são os mesmos do processo, de natureza jurídica, social e política, tanto em relação aos envolvidos quanto, indiretamente, à sociedade" (CAHALI, 2015, p. 43).

16 "O processo heterocompositivo judicial abordava conflito como se fosse um fenômeno relacionado exclusivamente à estrutura normativa positivada e, ao tratar exclusivamente daqueles interesses juridicamente tutelados, excluía aspectos do conflito que são possivelmente tão importantes quanto ou até mais relevantes do que aqueles juridicamente tutelados" (AZEVEDO, 2011, p. 21).
} 
Já a conciliação é um instituto que tem por objetivo chegar voluntariamente a um acordo neutro e conta com a participação de um terceiro - conciliador - que intervém, podendo inclusive sugerir propostas para fins de dirigir a discussão. Na conciliação o objetivo é o acordo. Nela, as partes, mesmo adversárias, devem chegar a um acordo para evitar o processo judicial ou para nele pôr um ponto final, se por ventura ele já existe (CAHALI, 2015). Justamente por isso, o conciliador sugere, orienta, interfere e aconselha as partes, sem analisar o conflito em profundidade ${ }^{17}$.

Ao delimitar conciliação e mediação ${ }^{18}$, observa-se que a diferença básica entre ambas se encontra na origem do conflito (aqui analisado se ele diz respeito a uma relação continuada, com existência de relação anterior entre os conflitantes - cunho subjetivo-; ou se tratava de uma relação esporádica - de cunho objetivo), na postura do mediador/conciliador ou nas técnicas por ele empregadas (CAHALI, 2015). Além disso, a conciliação tem por objetivo principal a pacificação do litígio processual mediante a elaboração de um acordo. Já a mediação pretende humanizar o conflito, restabelecendo a comunicação rompida entre os litigantes e tornando-a viável e, se possível, harmoniosa. $\mathrm{O}$ acordo é efeito secundário da mediação e não objetivo principal a ser perseguido como é o caso da conciliação.

Em síntese e de maneira bem objetiva, a mediação e a conciliação diferem:

a) quanto ao conflito: na conciliação existem conflitos esporádicos, sem relacionamento prévio ou posterior entre os conflitantes. Exemplo: relações de consumo ou acidente de trânsito; já na mediação existem conflitos nos quais os envolvidos possuem relações próximas anteriores ao litígio e que permanecerão (pelo menos assim se espera), íntegros após a Resolução do mesmo. Exemplo típico são os conflitos do Direito de Família, Direito Sucessório ou aqueles pertencentes às relações de amizade e vizinhança;

b) quanto ao papel do mediador/conciliador: na mediação há uma terceira pessoa que atua como mediador, ajudando os conflitantes a restabelecer a comunicação. O mediador não

\footnotetext{
17 Observa-se que, muitas vezes, a intervenção do conciliador ocorre (não deveria!) no sentido de forçar o acordo.

18 "Longe de pretender apresentar distinções definitivas entre formas autocompositivas de solução de conflitos, é importante trazer algumas reflexões distintivas entre conciliação e mediação a partir dos vínculos e relações entre as partes. A conciliação em um dos prismas do processo civil brasileiro é opção mais adequada para resolver situações circunstanciais, como uma indenização por acidente de veículo, em que as pessoas não se conhecem (o único vínculo é o objeto do incidente), e, solucionada a controvérsia, lavra-se o acordo entre as partes, que não mais vão manter qualquer outro relacionamento; já a mediação afigura-se recomendável para as situações de múltiplos vínculos, sejam eles familiares, de amizade, de vizinhança, decorrentes de relações comerciais, trabalhistas, entre outros. Como a mediação procura preservar as relações, o processo mediacional bem conduzido permite a manutenção dos demais vínculos, que continuam a se desenvolver com naturalidade durante e depois da discussão da causa" (BACELLAR, 2011, p. 35-36).
} 
sugere, não propõe, não orienta. O conciliador, ao contrário, é o terceiro que pode sugerir, propor, orientar e direcionar o debate e seus resultados;

c) quanto aos objetivos perseguidos: a mediação busca um tratamento adequado ao conflito que gere comunicação e satisfação dos envolvidos. O acordo pode ser uma consequência dessa dinâmica, mas um procedimento de mediação que não tenha se encerrado com um acordo não poderá ser chamado de inexitoso se possibilitou que os conflitantes voltassem a conversar. A mediação busca o consenso e a efetiva pacificação social. A conciliação tem por alvo principal alcançar o acordo, por isso é um procedimento focado na necessária composição entre as partes. O objetivo é solucionar o litígio mediante um acordo.

d) quanto às técnicas empregadas e à dinâmica das sessões: a mediação prevê o emprego de técnicas voltadas para a escuta e o desvelamento do real interesse envolvido no conflito. É um procedimento voltado aos conflitantes que se tornam protagonistas de suas histórias e da construção de respostas aos seus problemas. A mediação prevê sessões mais longas do que a conciliação, bem como a remarcação de tais sessões quando é necessário que o diálogo se mantenha e amadureça para que posteriormente sejam tomadas as decisões. Já a conciliação prevê o uso de técnicas de negociação mais voltadas para o acordo propriamente dito, ela estimula propostas e contrapropostas dos conflitantes e do conciliador. A conciliação acontece em sessões mais curtas e a hipótese de remarcação de novos encontros não é tão frequente.

Assim observa-se que mediação e conciliação são institutos afins, porém, diferentes. Cada um deles possui seus limites e possibilidades servindo a conflitos específicos, com características e formas de atuação também diferenciadas. Por isso distingui-los é importante ${ }^{19}$.

\subsection{Impropriedade terminológica quanto ao momento da mediação}

Tratando-se de institutos diferentes, também terão seu momento de realização em atos diferentes. Tanto o Código de Processo Civil quanto a Lei 13.140/2015 (Lei de Mediação), incorrem em um equívoco de identificação dos atos, talvez em razão exatamente da falta de definições tratada no tema anterior.

\footnotetext{
${ }^{19}$ Estudo abrangente pode ser realizado em SPENGLER, Fabiana, SPENGLER NETO, Theobaldo (Org.), Do conflito à solução adequada: mediação, conciliação, negociação, jurisdição e arbitragem. Santa Cruz do Sul: Esserenel Mondo, 2015.
} 
Derivado do latim de audire, que tem o sentido de escutar, atender, o termo audiência tem o sentido, no Direito Processual Civil de estar perante o juiz para um ato audível. Considera Tartuce (2016, p. 273):

\begin{abstract}
Com a evolução da prática e dos estudos processuais, a expressão passou a ser utilizada com maior requinte, sendo hoje identificada com uma situação em que um magistrado preside o ato; nessa medida, a audiência é considerada o ato processual solene realizado na sede do juízo que se presta para que o juiz possa colher prova oral, ouvir os procuradores das partes e proferir decisão.
\end{abstract}

Ou seja, ato presidido pelo magistrado. E aqui nasce o equívoco legislativo encontrado no art. 334 e seus parágrafos, bem como na Lei de Mediação (artigos 6 $6^{\circ}, 24$ e 27) ${ }^{20}$. Importante referir que é o próprio Conselho Nacional de Justiça que dá origem à confusão terminológica quando trata o ato como sessão (artigo $7^{\circ}$ ) e audiência (artigo 12-D) na Resolução 125. Ora, os atos de conciliação e de mediação não são realizados em uma audiência, mas sim em sessões.

É equivocado utilizar o termo "audiência" para denominar o encontro das pessoas e dos profissionais envolvidos na disputa com o objetivo de dialogar para alcançar um acordo. Chamar de audiência esse encontro, que até então era denominado de "sessão" ou de "reunião" induz a equívoco. Tal se dá porque a audiência ${ }^{21}$ é um ato processual solene, na maioria das situações público, e que deverá ser presidido pelo juiz. Esse é o primeiro percalço pois atualmente existe a possibilidade de que a mediação e a conciliação possam ser feitas por pessoas que tenham recebido treinamento específico, que estejam formadas há mais de dois anos em qualquer área do conhecimento.

Nesses termos, a audiência envolve sempre a figura do juiz, mas o próprio CPC abre a possibilidade de que a reunião de mediação/conciliação - nele chamado de audiência - seja feita por pessoas que não são Juízes. Por fim, a audiência processual, permite, dentre outras coisas, que seja colhida a prova oral e que sejam ouvidas pessoalmente as partes e seus

\footnotetext{
${ }^{20}$ Vale a leitura dos comentários de Gimenez, Kops e Knod ao artigo 27 da Lei de Mediação, encontrado em SPENGLER, Fabiana e SPENGLER NETO, Theobaldo (Org.), Mediação, conciliação e arbitragem, Rio de Janeiro: FGV Editora, 2016.

21 “Audiência, s.f.- Diz-se do ato de ouvir a parte, de admitir que ela fale, em juízo, na defesa de suas pretensões. É também sessão pública solene em que o juiz singular, ou as juntas trabalhistas, promovem a instrução final da causa e os debates orais, passando, em seguida, ao julgamento do litígio ou a sua conversão em diligência se não foi possível resolver a contenda mediante conciliação das partes” (NEVES, 1990, p. 78).
} 
procuradores. Essa perspectiva pode ser aplicada a conciliação, mas não serve para a mediação.

O Núcleo de Estudos de Mediação vinculado à Associação dos Juízes do Rio Grande do Sul - AJURIS, coordenado pela Desembargadora Genaceia da Silva Alberton já pautou que as conciliações e as mediações realizadas tanto em centros judiciários quanto em privados devem ser qualificadas como sessões e não audiências (TARTUCE, 2016). Nesses atos inexiste a figura da autoridade que os presida (juiz), mas sim de um terceiro que tem a tarefa de ser um facilitador para que se realize um diálogo salutar.

Dessa forma, e como corolário, importa definir que conciliações e mediações devem ser tratadas em sessões e não audiências, seja em âmbito público ou privado. Somente serão realizadas em audiências quando presididas por magistrados.

\section{A AUTOCOMPOSIÇÃO NO CPC E AS CONTROVÉRSIAS SURGIDAS}

Como toda legislação nova, o CPC em vigor mereceu elogios e críticas. Por maior que tenha sido o esforço de todos os colaboradores na construção, algumas críticas são devidas, outras imerecidas. Entretanto, aí está e deve ser respeitado, interpretado e cumprido de forma a ser melhor do que o substituído em nome do bom andamento jurisdicional.

$\mathrm{Na}$ busca da interpretação das novas normas de modo a cumpri-las, dois pontos merecem discussão atenta: o primeiro, a possibilidade ou não de aplicação da multa prevista no art. 334 , parágrafo $8^{\circ}$, às partes ausentes de sessões de mediação. $\mathrm{O}$ segundo, a legalidade ou não de aplicação da multa pela ausência das partes às sessões ou audiências de conciliação ou de mediação designadas no curso da demanda, e não na fase prevista processualmente.

\subsection{Inaplicabilidade da multa do artigo 334, CPC quando da ausência às sessões} de mediação

Vale buscar a redação do parágrafo oitavo do artigo 334:

O não comparecimento injustificado do autor ou do réu à audiência de conciliação é considerado ato atentatório à dignidade da justiça e será sancionado com multa de 
até dois por cento da vantagem econômica pretendida ou do valor da causa, revertida em favor da União ou do Estado.

De plano se lê que o artigo trata exclusivamente da audiência de conciliação, apenas. Não inclui a sessão de mediação, o que exclui a possibilidade de aplicação da multa, porque ausente imposição legal. Nessa ordem deve ser observada a norma constitucional que prevê de modo indubitável que "ninguém será obrigado a fazer ou deixar de fazer alguma coisa senão em virtude de lei" (inciso II, do art. $5^{\circ}$, da CF).

Assim, não prevendo expressamente o parágrafo oitavo a obrigatoriedade de presença das partes à sessão de mediação, impossível a caracterização de ato atentatório à dignidade da justiça. Não há que se punir por ato não exigível.

Vale lembrar que o contemptofcourtchegou à legislação brasileira no Código de 1973 visando coibir a prática de atos atentatórios, em especial nos processos de execução. Objetivava, como ainda o faz, reprimir a prática de atos que visem procrastinar o andamento processual ou mesmo impedir o sucesso da prestação jurisdicional. Assim, em resumo, a prática dolosa de atos. À toda evidência, não é o que se vê no art. 334 do CPC.

De outra banda, e saindo do aspecto estritamente legal, basta associar a pretendida obrigação de comparecimento com os princípios básicos da mediação de $\operatorname{conflitos}^{22}$, dentre eles a voluntariedade em participar do ato (SPENGLER, 2014). O simples fato de impor o comparecimento sob pena de multa acarreta na quebra de um dos aspectos fundamentais para um bom resultado.

Dessa forma, tem-se que mais do que indevida a imposição da multa prevista pelo art. 334, em seu parágrafo oitavo, do CPC às partes que não comparecerem injustificadamente à sessão de mediação, é ilegal.

\subsection{Inaplicabilidade da multa do art. 334, CPC quando a audiência não ocorrer} no primeiro momento processual

\footnotetext{
${ }^{22}$ Para uma absoluta compreensão do instituto - mediação - considere-se a leitura de SPENGLER (2016a); CALMON, (2013) e TARTUCE (2016).
} 
Outro aspecto controvertido é o tempo da audiência de conciliação ou de mediação. Aqui, tempo no sentido de localização no curso do processo. Para tanto, há que se trazer primeiro o caput do art. 334, do CPC:

\footnotetext{
se a petição inicial preencher os requisitos essenciais e não for o caso de improcedência liminar do pedido, o juiz designará audiência de conciliação ou de mediação com antecedência mínima de 30 (trinta) dias, devendo ser citado o réu com pelo menos 20 (vinte) dias de antecedência.
}

Na sequência, o artigo 335 abre o capítulo “da contestação". Aponta o prazo de 15 dias para a oferta, iniciando, dentre três hipóteses, "I - da audiência de conciliação ou de mediação, ou da última sessão de conciliação, quando qualquer parte não comparecer ou, comparecendo, não houver autocomposição". Portanto, é inteligência da soma dos artigos, que o momento para que a audiência de conciliação ou a sessão de mediação ocorra é exclusivamente aquele que sucede o recebimento da petição inicial e a citação e antecede a contestação.

Em nome da insuficiência de condições materiais e/ou humanas ou do acúmulo de demandas, em algumas comarcas brasileiras tem-se noticiado a não designação dessa audiência. Aplica-se o artigo 231, I, do $\mathrm{CPC}^{23}$, abrindo o prazo contestacional a partir da juntada aos autos da prova da citação.

A questão que se levanta, então é a possibilidade de designação de audiência de conciliação após esgotada a fase postulatória, e antes do saneamento? Na prática, voltar-se-ia à audiência preliminar (artigo 331, CPC/73), na qual o juiz, não havendo composição, passava a sanear o feito em audiência. Ora, a possibilidade de designação de audiência conciliatória passa pelo crivo de conveniência do juiz, a qualquer tempo. Não poderá ele, porém, fazer uso do ato de pressão contido no parágrafo oitavo do artigo. 334 para compelir as partes a estarem presentes. Esta audiência será realizada nos termos do artigo 139, V, do CPC, podendo ele utilizar-se dos conciliadores e dos mediadores.

O aspecto que define a impossibilidade da aplicação da multa é exatamente o objetivo dela. É o de trazer as partes a uma oportunidade de autocomposição, antes da contestação;

\footnotetext{
${ }^{23} \mathrm{Na}$ verdade retorna ao que era a regra, à época do finado CPC/73.
} 
antes do recrudescimento dos ânimos, possibilitando efetivamente o diálogo. A audiência de conciliação após já esgotados os momentos de dizer de cada um, foge do objetivo pretendido.

Ademais, o artigo 139, V traz carga de opção de condução da audiência exatamente contrária do parágrafo primeiro do artigo 334. Neste, a atuação será, preferencialmente dos conciliadores ou dos mediadores. Naquele, do juiz, o qual poderá utilizar-se dos auxiliares. Portanto, passa a ser indevida a imposição da multa pelo não comparecimento. Chega-se, pois, a um tema já tratado por Wambieret all (2015, p. 139), que é a conveniência ou não de o juiz presidir sessão de mediação:

hoje se utilizam os termos mediação e conciliação como significantes de processos que levam à realização do acordo. A conciliação é um mecanismo em que o juiz tem presença maior, na medida em que pode induzir as partes, estimulá-las à composição mediante proposta de solução. A mediação talvez envolva um mergulho mais profundo na psique das partes, porque consiste em fazer com que elas mesmas encontrem o caminho do acordo.

Certamente, dirão coisas que não diriam, se fossem litigar, colocar-se uma contra a outra. Estas informações o juiz não poderá ter, porque não as poderá usar para decidir.

Ao juiz remanesce o poder/dever de tentar a conciliação, tal como tradicionalmente concebida. Todavia, o "mergulho" nos processos psicológicos deve ser feito por profissional capacitado, protegido pela devida confidencialidade. A essas sessões o juiz, a rigor, não deve estar presente.

Há que se resguardar a quem incumbe julgar o seu espaço, com as condições existentes nos autos. Mesmo que com as condições técnicas para mediar, uma vez não obtido resultado positivo, deverá dar-se por impedido para prosseguir na instrução e julgamento. Nessa linha, em optando pela designação de sessão de mediação, deverá o juiz remeter os autos aos mediadores judiciais já definidos.

\section{CONCLUSÃO}

Indubitavelmente a busca pela autocomposição é o melhor caminho para chegar a um resultado menos oneroso econômica e psicologicamente para as partes. E o CPC vigente, ao 
trazer para o processo civil a possibilidade de tratamento por meio da mediação - a conciliação já se tinha no CPC/73 - deu um passo importante.

Da mesma forma correta a alocação da audiência de conciliação e a sessão de mediação para os primórdios do processo. É o momento menos convulsionado em que as partes poderão se encontrar, dialogar e quiçá compor. Momento que poderá se desmembrar em etapas, quando os conflitantes assim desejarem.

Dessa forma é fundamental que se interprete a oportunidade de outros momentos de conciliação e/ou de mediação como possível e sempre aconselhável. Deve o julgador, encontrando receptividade das partes, oportunizar a autocomposição. Não pode, porém, exatamente em razão das motivações que alocam o ato tratado pelo art. 334 do CPC para o início do processo, aplicar qualquer tipo de coação no curso dele. A multa do parágrafo oitavo está destinada a compelir os conflitantes a participar de um ato inaugural, ainda desarmados (em especial o réu).

Porém, há que se preservar a proposta de composição, o que somente ocorre quando as partes estiverem prontas a ouvir e a serem ouvidas. E esse desprendimento somente ocorrerá quando a participação não for imposta, em especial para fins de realização de sessões de mediação.

Exatamente nessa linha de interpretação é que o parágrafo oitavo do art. 334, do CPC, omitiu a mediação da pena de multa (mantendo apenas a conciliação no seu texto). Porque somente será eficaz a mediação com espontaneidade, com liberdade, com a participação das partes (e não de procuradores) e de mediadores capacitados para tal.

Importa que as partes compreendam a importância do ato. Mas também que os patronos esclareçam a elas os benefícios da composição. E que os magistrados, como lembra Dinamarco $(2009$, p. 76) ao analisar a extinta audiência preliminar, percebam que não se está diante de mais um ato processual, mas de um momento em que se busca mais do que a paz do Direito, a pacificação social.

\section{REFERÊNCIAS}

ABREU, Leonardo Santana de. Comentários ao art. 331 do CPC - Da audiência preliminar. Revista Páginas de Direito, Porto Alegre, ano 7, $\mathrm{n}^{\circ}$ 678, 24 de novembro de 2007. Disponível em: http://www.tex.pro.br/home/artigos/71-artigos-nov-2007/5724-comentarios-ao-art-331do-cpc-da-audiencia-preliminar-5556, acesso em 06 de janeiro de 2017. 
BUENO, Cássio S. Novo Código de Processo Civil anotado. São Paulo: Saraiva, 2016.

CALMON, Petrônio, Fundamentos da Mediação e da Conciliação. $2^{\mathrm{a}}$ edição, Brasília: Gazeta Jurídica, 2013.

CASTRO FILHO, José. A conciliação no processo civil, http://www.direito.ufmg.br/revista/index.php/revista/article/viewFile/573/540, acesso em 05 de janeiro de 2017.

DIANMARCO, Cândido R. Vocabulário do processo civil. São Paulo: Malheiros, 2009.

PINHO, Humberto D. B. Audiência de conciliação ou de mediação: o art. 334 do CPC/2015 e a nova sistemática do acordo judicial, in Processo em Jornadas, Salvador: Podium, 2016.

SPENGLER, Fabiana M. Retalhos de Mediação. Santa Cruz do Sul: Esserenel Mondo, 2014.

SPENGLER, Fabiana M. Mediação de conflitos - da teoria à prática. Porto Alegre: Livraria do Advogado, 2016a.

SPENGLER, Fabiana M. Da jurisdição à mediação - por uma outra cultura no tratamento de conflitos, Ijuí: Editora Unijuí, 2016b.

SPENGLER, Fabiana, SPENGLER NETO, Theobaldo (Org.), Do conflito à solução adequada: mediação, conciliação, negociação, jurisdição e arbitragem. Santa Cruz do Sul: Esserenel Mondo, 2015.

SPENGLER, Fabiana M., SPENGLER NETO, Theobaldo. Mediação, conciliação e arbitragem, artigo por artigo. Rio de Janeiro: Editora LGV, 2016.

TARTUCE, Fernanda. Mediação dos conflitos civis. São Paulo: Método, 2016.

WAMBIER, Teresa A. A., et all. Primeiros comentários ao novo Código de Processo Civil artigo por artigo. São Paulo: Revista dos Tribunais, 2015.

Recebido em : 30/08/2017.

Aprovado em: 19/09/2017 